\title{
O gênero Chaptalia (Asteraceae, Mutisieae) no Rio Grande do Sul, Brasil
} The genus Chaptalia (Asteraceae, Mutisieae) in the state of Rio Grande do Sul, Brazil

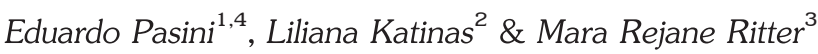

\begin{abstract}
Resumo
O gênero Chaptalia compreende cerca de 70 espécies, distribuídas desde o norte dos Estados Unidos até o centro da Argentina, sendo que no Brasil ocorrem 17 espécies. Dentre os caracteres diagnósticos do gênero podem ser citados as flores trimórficas, o hábito herbáceo e a ausência de estaminódios nas flores. O trabalho teve como objetivo o levantamento das espécies de Chaptalia no estado do Rio Grande do Sul. Foi possível confirmar a ocorrência de 10 espécies: C. arechavaletae, C. cordifolia, C. exscapa, C. graminifolia, C. ignota, C. integerrima, C. mandonii, C. nutans, C. piloselloides e C. runcinata. Chaptalia sinuata é colocada em sinonímia de C. integerrima. O trabalho apresenta descrições das espécies, chaves de identificação, ilustrações, dados sobre conservação e informações gerais.
\end{abstract}

Palavras-chave: Compositae, conservação, Mata Atlântica, Pampa.

\begin{abstract}
The genus Chaptalia is represented by ca. 70 species, from northern United States to the center of Argentina; in Brazil there are 17 species. Among the recognizable features of the genus are trimorphic florets, herbaceous habit and florets without staminodes. The present work aimed to survey the native species of Chaptalia in the state of Rio Grande do Sul. The occurrence of 10 species in the State is confirmed: C. arechavaletae, C. cordifolia, C. exscapa, C. graminifolia, C. ignota, C. integerrima, C. mandonii, C. nutans, C. piloselloides e C. runcinata. Chaptalia sinuata is placed by first time as a synonym of $C$. integerrima. The study presents species descriptions, an identification key, illustrations, conservation data and general information.
\end{abstract}

Key words: Compositae, conservation, Atlantic Forest, Pampa.

\section{Introdução}

Mutisieae s.str. é constituída por aproximadamente 14 gêneros e 200 espécies predominantemente sul-americanas com representantes na América Central, Ásia, África e Austrália (Funk et al. 2009). Chaptalia Vent. é o maior gênero do Complexo-Gerbera representado por cerca de 70 espécies, das quais 17 são citadas para o Brasil (Burkart 1944; Mondin 1996; Boldrini et al. 2009; Monge \& Roque 2012; Pasini \& Ritter 2012). O gênero é estritamente americano, ocorrendo desde o sul dos Estados Unidos até a região do Rio da Prata na Argentina, importante centro de diversidade (Burkart 1944). Pode ser reconhecido por tratar- se de ervas perenes e escaposas, com flores trimórficas sem estaminódios, ramos do estilete papilosos e cipselas rostradas ou atenuadas (Katinas et al. 2008). Apesar das 70 espécies, Katinas et al. (2008) indicam uma diminuição do atual número para 20 a 35, devido a delimitação infragenérica ainda incerta de alguns gêneros do Complexo-Gerbera. Burkart (1944) realizou a primeira revisão do gênero, enfatizando as espécies argentinas. $\mathrm{O}$ autor dividiu as espécies em sete seções: Archichaptalia, Euchaptalia (= Chaptalia), Pseudotrichocline, Loxodon, Lierberkuhna, Leria e Microchaptalia.

No Brasil as espécies distribuem-se em todos os Biomas, entretanto a maioria é encontrada nas Regiões Sul e Sudeste. O gênero

\footnotetext{
${ }^{1}$ Universidade Federal do Rio Grande do Sul, Programa de Pós-graduação em Botânica, Av. Bento Gonçalves 9500, 91501-970, Porto Alegre, RS, Brasil.

${ }^{2}$ Museo de La Plata, División Plantas Vasculares, Paseo del Bosque s/n, 1900, La Plata, Argentina.

${ }^{3}$ Universidade Federal do Rio Grande do Sul, Depto. Botânica, Programa de Pós-graduação em Botânica, Av. Bento Gonçalves 9500, 91501-970, Porto Alegre, RS, Brasil.

${ }^{4}$ Autor para correspondência: eduardo.pasini@yahoo.com.br
} 
ocorre em todo o estado do Rio Grande do Sul, nas diferentes fisionomias campestres e florestais do Bioma Pampa e nos campos do Planalto e florestas com araucária pertencentes ao Bioma Mata Atlântica.

O presente trabalho objetivou a análise taxônomica das espécies nativas de Chaptalia no Rio Grande do Sul, através do levantamento florístico e revisões de bibliografia e de herbários do sul do Brasil e países adjacentes (Argentina e Uruguai). Através disso, foi possível confirmar a ocorrência de 10 espécies. O estudo apresenta descrições atualizadas, chave de identificação, ilustrações, status de conservação e informações gerais.

\section{Material e Métodos}

Para o presente estudo foram realizadas expedições de coleta de material botânico, observações no campo, consultas em herbários do sul do Brasil e países limítrofes e revisão da literatura histórica e recente. As coletas abrangeram todas as regiões fisiográficas do Rio Grande do Sul, conforme Fortes (1959). O material coletado foi herborizado e depositado no herbário do Instituto de Biociências/Universidade Federal do Rio Grande do Sul (ICN). Os seguintes herbários foram revisados: CRI, CTES, ESA, FLOR, FURB, GH, HAS, HB, HBR, HUEFS, HUFU, HURG, ICN, LP, M, MBM, MO, MPUC, MVFA, MVJB, MVM, NY, PACA, SALLE, SMDB, SPF, SI e US citados por sua sigla internacional de acordo com Thiers (continuously updated). Além desses foram revisados os herbários da Universidade de Caxias do Sul e da Universidade de Passo Fundo, cujas respectivas siglas não oficiais são HUCS e RSPF. Foram consultados materiais digitalizados disponibilizados na $W e b$ por herbários internacionais como $\mathrm{K}, \mathrm{P}, \mathrm{GOET}$, MO, LINN, B e $\mathrm{F}$, nos quais encontra-se depositada a maior parte do material-tipo deste gênero.

Os caracteres utilizados para a descrição das espécies basearam-se nos citados na literatura consultada, analisados em materiais coletados e depositados em herbários. A terminologia utilizada para a descrição dos caracteres morfológicos vegetativos seguiram Font Quer (1953), Radford et al. (1974), Gonçalves \& Lorenzi (2007) e Beentje (2010); para caracteres morfológicos reprodutivos, Barroso (1991), Roque \& Bautista (2008) e Funk et al. (2009). As medidas de comprimento e largura foram tomadas com auxílio de paquímetro digital e os valores das medidas nas descrições correspondem aos extremos encontrados. Dados sobre habitat, floração e frutificação e distribuição geográfica foram obtidos através da bibliografia consultada, informações das fichas do material examinado nos herbários e observações no campo. Na seção material examinado e selecionado, utilizou-se as seguintes siglas para designar o estágio fenológico do material: flor (fl.), fruto (fr.) e estéril (est.). A distribuição geográfica das espécies no estado do Rio Grande do Sul é apresentada conforme as regiões fisiográficas de Fortes (1959): Alto Uruguai, Campanha, Campos de Cima da Serra, Depressão Central, Encosta Inferior do Nordeste, Encosta Superior do Nordeste, Encosta do Sudeste, Litoral, Missões, Planalto Médio e Serra do Sudeste. Os biomas citados seguem o conceito do IBGE (2004). As informações sobre o status de conservação das espécies no estado do Rio Grande do Sul, seguiram os critérios propostos pelo IUCN (2011).

\section{Resultados e Discussão}

Chaptalia Vent. nom. cons. Descr. pl. nouv., fasc. 7: pl. 61. 1802. Tipo: Chaptalia tomentosa Vent.

Ervas perenes ou anuais, acaulescentes, escaposas. Raízes fusiformes de aspecto fasciculado, com ou sem rizoma. Folhas rosetadas, discolores ou concolores, sésseis ou pecioladas, base atenuada, lâminas lanceoladas, oblongas, oblanceoladas, ovadas, liradas ou cordadas, margens inteiras, lobadas, sinuadas, runcinadas, crenadas ou denteadas, ápice obtuso, agudo ou acuminado, face adaxial glabra, pilosa, serícea ou tomentosa, face abaxial tomentosa a lanosa. Inflorescências monocefálicas, escapo ereto ou sinuoso, elongado-se na floração e frutificação, bracteado ou ebracteado. Capítulos disciformes ou radiados, heterógamos, casmógamos ou cleistógamos, eretos, recurvados ou nutantes, ocasionalmente nutante no início da floração e posteriormente ereto; receptáculo epaleáceo; invólucro campanulado, cilíndrico a hemisférico; brácteas involucrais multiseriadas, imbricadas, eretas ou recurvadas, geralmente com as internas gradualmente maiores do que as externas. Flores trimórficas. Flores do raio pistiladas, uniseriadas, sem estaminódios, corola ligulada ou bilabiado-ligulada, de coloração branca, amarelo-claro, rosa, roxo, violeta ou avermelhado, lábio abaxial liguliforme, lábio adaxial ausente 
ou pouco desenvolvido, irregularmente bífido, lanceolado, irregularmente 3-denteado no ápice; estilete bífido, ramos do estilete acuminados, papilosos na face dorsal. Flores intermediárias pistiladas, sem estaminódios, corola filiforme, de coloração branca à esverdeada, irregularmente denteada no ápice; estilete bífido, exserto, ramos do estilete acuminados, papilosos na face dorsal. Flores do disco andróginas, corola bilabiada a tubuloso-bilabiadas, de coloração branca à esverdeada, lábio abaxial 3-lobado, lábio adaxial bífido; apêndices apicais das anteras obtusos a agudos; apêndices basais das anteras caudados; estilete bífido, ramos do estilete arredondados, papilosos na face dorsal. Cipselas longamente ou curtamente rostradas no ápice, cilíndricas ou fusiformes, glabras ou com tricomas duplos (Zwillingshaare) e glandulares distribuídos em toda a superfície ou apenas na base; pápus formado por cerdas escabrosas.

\section{Chave para as espécies de Chaptalia ocorrentes no Rio Grande do Sul}

1. Plantas com inflorescências sem escapo na floração

3. C. exscapa

1'. Plantas com inflorescências com escapo na floração

2. Folhas pecioladas, lâminas cordadas

2. C. cordifolia

2'. Folhas sésseis, atenuadas na base, lâminas nunca cordadas

3. Folhas com lâminas liradas

8. C. nutans

3'. Folhas com lâminas nunca liradas

4. Plantas com escapo floral ebracteado

6. C. integerrima

4'. Plantas com escapo floral apresentando brácteas subuladas ao longo de toda a extensão

5. Folhas com margens crenado-serreadas, escapo apresentando 20-35 brácteas subuladas

1. C. arechavaletae

5'. Folhas com margens crenado-denteadas, sinuado-denteadas, denteadas, irregularmente denteadas, serreadas a pinatissectas ou inteiras, escapo apresentando até 16 brácteas subuladas 6

6. Pápus da cipsela com 13-20 mm de comprimento, folhas com margens crenadodenteadas 5. C. ignota

6'. Pápus da cipsela com 4-12 mm de comprimento, folhas com margens sinuadodenteadas, denteadas, irregularmente denteadas, serreadas a pinatissectas ou inteiras

7. Plantas com escapo floral de até $56 \mathrm{~cm}$ de comprimento, folhas com até $40 \mathrm{~cm}$ de comprimento com margem inteira e revoluta, cipsela glabra

4. C. graminifolia

7'. Plantas com escapo floral de até $38 \mathrm{~cm}$ de comprimento, folhas com até $21 \mathrm{~cm}$ de comprimento com margem denteada, irregularmente denteada ou sinuado-denteada, eventualmente revoluta, cipsela com tricomas em toda a superfície ou restritos à base

8. Folhas com lâminas coriáceas, nervuras secundárias impressas na face adaxial, margem eventualmente revoluta, cipsela com tricomas em toda a superfície 7. C. mandonii

8'. Folhas com lâminas papiráceas, nervuras nunca impressas na face adaxial, margem nunca revoluta, cipsela com tricomas restritos à base

9. Cipsela 4-6 costada, com 8-9 mm de comprimento, rostro com 4-6 mm de comprimento 10. C. runcinata

9'. Cipsela 7-8 costada, com 6-7,5 $\mathrm{mm}$ de comprimento, rostro com 1,5-5 mm de comprimento 9. C. piloselloides 


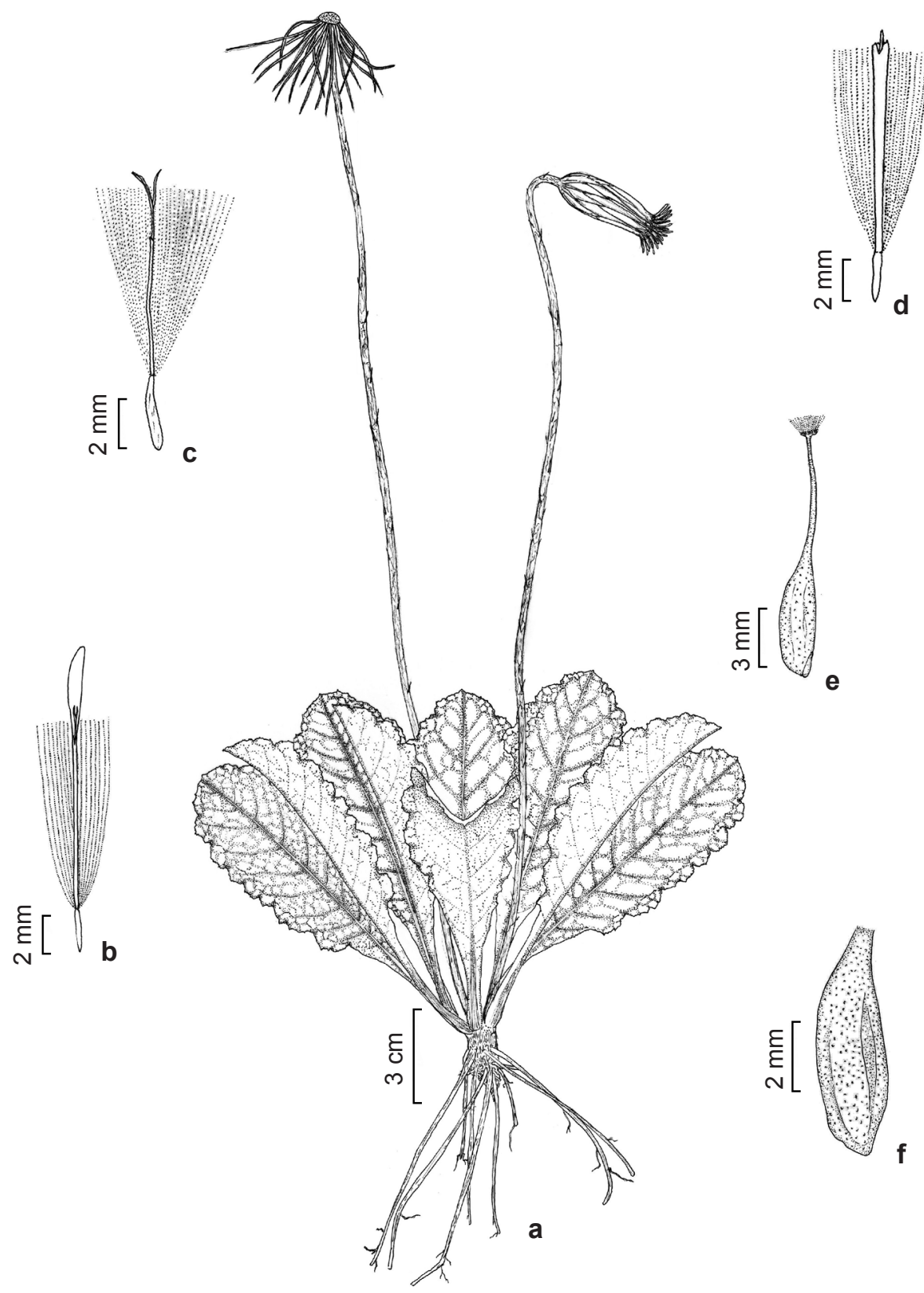

Figura 1 - a-f. Chaptalia arechavaletae Hieron. - a. hábito (Burkart 7899); b. flor do raio; c. flor intermediária; d. flor do disco; e. cipsela; f. detalhe da cipsela (Burkart 18117).

Figure 1 - a-f. Chaptalia arechavaletae Hieron. - a. habit (Burkart 7899); b. ray florets; c. intermediate floret; d. disc floret; e. cypsela; f. detail of the cypsela (Burkart 18117).

1. Chaptalia arechavaletae Hieron., Anales Mus. Nac. Montevideo 2: 14. 1904. Tipo: URUGUAI: MONTEVIDÉU, Melilla, III.1896, J. Arechavaleta s.n. (Holótipo: B; Imagem digitalizada: F!; Isótipo: MVM!).

Fig. 1a-f

Plantas 14-35 cm alt. Raízes enegrecidas. Folhas sésseis, lâminas papiráceas, obovadas ou oblanceoladas, 4,5-17 × 2-6 cm, base atenuada, margem crenado-serreada, ápice arredondado a agudo, apiculado, face adaxial glabra, face abaxial tomentosa. Escapo 10-50 × 0,05-0,1 cm, piloso a tomentoso, brácteas 20-35, subuladas, vermelhas. Capítulo nutante; invólucro 1,8-3 $\times 1,2-4,5 \mathrm{~cm}$, cilíndrico, hemisférico ou 
campanulado; brácteas involucrais 5-6 seriadas, subuladas, pubescentes ou glabras em ambas as faces, ápice e nervura central lilases. Flores do raio brancas ou lilases, tubo $6-8,5 \mathrm{~mm}$ compr., lábio abaxial 4,8-11 mm compr., lábio adaxial ausente; estilete 7,5-12 mm compr., ramos do estilete 1,5-3 mm compr. Flores intermediárias brancas, tubo 3,5-6,8 $\mathrm{mm}$ compr.; estilete 7,5-10 mm compr., ramos do estilete $1-3 \mathrm{~mm}$ compr. Flores do disco brancas, tubo 7-11,5 $\mathrm{mm}$ compr., lábio abaxial 1,6-2,6 $\mathrm{mm}$ compr., lábio adaxial 2-2,7 mm compr.; estilete 8,4-10 mm compr., ramos do estilete $1-1,5 \mathrm{~mm}$ compr.; anteras 4,5-5 $\mathrm{mm}$ compr., apêndices apicais truncados ou obtusos. Cipsela fusiforme, 5-6 costada, 12-20 mm compr., rostrada, rostro 4-10 mm compr., tricomas esparsos; pápus branco, amarelado ou arroxeado, 16-22 $\mathrm{mm}$ compr.

Material examinado: Hulha Negra, 22.IX.1977, fl., A.M. Girardi-Deiro 465 (CNPO).

Material adicional selecionado: ARGENTINA. BUENOS AIRES: Part. San Isidro, Villa Elisa, 24.XI.1935, fr., A. Burkart 7899 (SI). Part. Baradero, 7.XII.2002, fl., S.T. Robles et al. 1185 (LP). CORRIENTES: XI.1914, fl., Verón (LP 6287). ENTRE RÍOS: Dep. Gualeguay, 23.X.1949, fl., A. Burkart 18117 (SI). MISIONES: Dep. Capital, 15.I.1908, fr., E. Ekman 1012 (LP). URUGUAI. MONTEVIDEO: Montevideo, XII.1938, fl. e fr., $J$. Chebataroff 1624 (LP). CANELONES: Arroyo Canelón Chico, 24.X.1935, fl., Rosengurtt B142 (LP). FLORIDA: Cerro Colorado, 3.X.1943, Gallinal et al. PE-5058 (LP). LAVALLEJA: Minas, 3.X.1937, fl., Rosengurtt B2146 (LP). MALDONADO: Cerro de Las Animas, XII.1939, fl. e fr., J. Chebataroff 2763 (LP).

Distribui-se pela Argentina, Uruguai e Região Sul do Brasil (Rio Grande do Sul). No Rio Grande do Sul é restrita à região da Campanha, Bioma Pampa, habitando áreas abertas com vegetação campestre, subarbustiva ou arbustiva, geralmente em solo seco e rochoso ou em ambientes influenciados pela ação antrópica. A espécie possui apenas um registro para o Brasil, no Rio Grande do Sul (A.M. Girardi-Deiro CNPO). Entretanto, Monge \& Roque (2012) citam a espécie como ocorrendo no Brasil em Santa Catarina, indicando o voucher A.M. Girardi-Deiro 465 (CNPO). Entretanto, pode ter ocorrido um engano, uma vez que o município de Hulha Negra localiza-se no Rio Grande do Sul, próximo à fronteira com o Uruguai. No Estado a espécie pode ser enquadrada, conforme os critérios propostos pelo IUCN (2001) como criticamente em perigo (CR B2b(ii); D).
Floresce de setembro a dezembro. É facilmente distinguível pelas folhas papiráceas, crenado-denteadas com nervuras secundárias impressas e escapo com 20 a 35 brácteas. $O$ epíteto homenageia J. Arechavaleta, botânico uruguaio que primeiramente coletou a espécie em 1896. Não foram encontrados, na literatura ou material examinado, nomes populares atribuídos à espécie.

2. Chaptalia cordifolia (Baker) Cabrera, Fl. Ilustr. Catarin.: 67. 1973. Trichocline cordifolia Baker, Bull. Misc. Inform. Kew: 197. 1892. Tipo: BRASIL. RIO DE JANEIRO: Rio de Janeiro, s.d., A. Glaziou 18320 (Lectótipo: designado por Cabrera \& Klein (1973) K; Imagem digitalizada: K!).

Fig. 2a-f

Plantas 18-35 cm alt. Raízes marrons. Folhas pecioladas, lâminas papiráceas a coriáceas, cordadas, 3-15 × 2,5-12 cm, base cordada, margem denteada, ápice arredondado a agudo, apiculado, face adaxial glabra, eventualmente serícea em folhas jovens, face abaxial tomentosa a lanosa, nervuras secundárias impressas, pecíolo piloso a tomentoso, 3-25 cm compr. Escapo $7-58 \times 0,1-0,3 \mathrm{~cm}$, piloso a lanoso, ebracteado. Capítulo nutante; invólucro $1,2-1,8 \times 1-2 \mathrm{~cm}$, hemisférico, campanulado ou cilíndrico; brácteas involucrais 5-6 seriadas, lanceoladas a lineares, lanosas na face adaxial, ápice e nervura central lilases. Flores do raio brancas, tubo $3-6,5 \mathrm{~mm}$ compr., lábio abaxial 6-9 $\mathrm{mm}$ compr., lábio adaxial bífido ou irregularmente bífido ou ausente; estilete $6-8,5 \mathrm{~mm}$ compr., ramos do estilete $0,5-1 \mathrm{~mm}$ compr. Flores intermediárias brancas, tubo 4-7,5 mm compr.; estilete 5-7,8 mm compr., ramos do estilete $0,5-0,8 \mathrm{~mm}$ compr. Flores do disco brancas, tubo 4,5-6 mm compr., lábio abaxial 1,5-2,8 $\mathrm{mm}$ compr., lábio adaxial $1,5-2,8 \mathrm{~mm}$ compr.; estilete $6-7,8 \mathrm{~mm}$ compr., ramos do estilete $0,4-0,7 \mathrm{~mm}$ compr.; anteras 3,7-5 mm compr., apêndices apicais agudos. Cipsela fusiforme, 5 costada, $8,5-10 \mathrm{~mm}$ compr., rostrada, rostro 3-4,5 $\mathrm{mm}$ compr., tricomas esparsos; pápus branco ou branco-amarelado, 4,5-9,5 mm compr.

Material selecionado: Cambará do Sul, em direção a São Francisco de Paula, 2909'55"'S, 5004'79'W, 10.XII.2010, fr., E. Pasini et al. 551 (ICN).

Material adicional selecionado: PARANÁ: Antonina, 12.I.2006, fl., O.S. Ribas \& J.M. Silva 7129 (MBM). SANTA CATARINA: Bom Jardim da Serra, II.1989, fl., M. Sobral et al. 6485 (MBM). Bom Retiro do Sul, 15.XII.1948, fl. e fr., R. Reitz 3778 (HBR, PACA). 

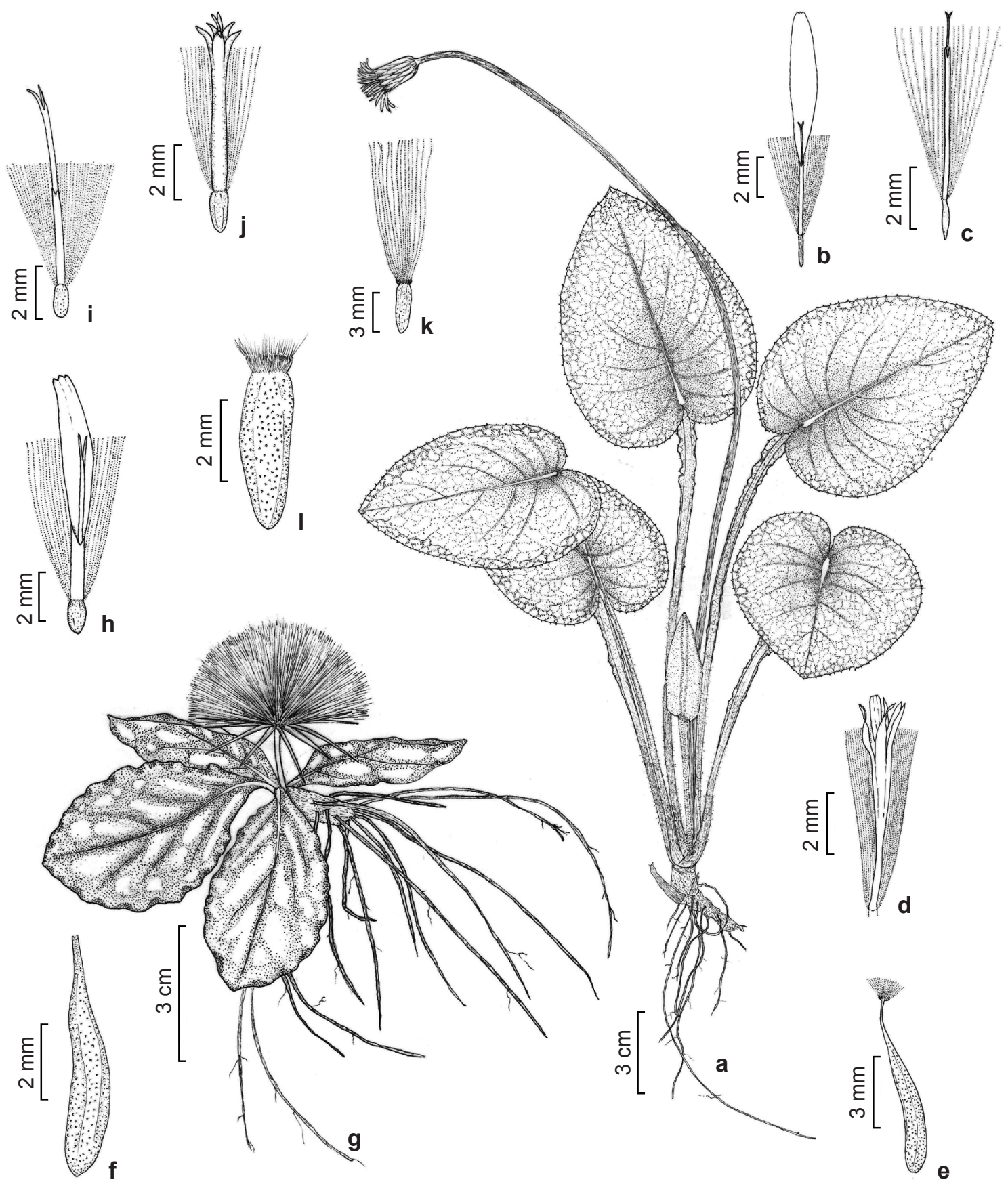

Figura 2 - a-f. Chaptalia cordifolia (Baker) Cabrera - a. hábito (Ribas \& Silva 7129); b. flor do raio (Reitz 3778); c. flor intermediária (Reitz 3778); d. flor do disco (Reitz 3778); e. cipsela (Reitz 3778); f. detalhe da cipsela. g-1. Chaptalia exscapa (Pers.) Baker - g. hábito; h. flor do raio; i. flor intermediária; j. flor do disco; k. cipsela; 1. detalhe da cipsela (Wasum s.n. HUCS 3220).

Figure 2 - a-f. Chaptalia cordifolia (Baker) Cabrera - a. habit (Ribas \& Silva 7129); b. ray floret (Reitz 3778); c. intermediate floret (Reitz 3778); d. disc floret (Reitz 3778); e. cypsela (Reitz 3778); f. detail of the cypsela. g-l. Chaptalia exscapa (Pers.) Baker - g. habit; h. ray floret; i. intermediate floret; j. disc floret; k. cypsela; 1. detail of the cypsela (Wasum s.n. HUCS 3220). 
Distribui-se pelas Regiões Sudeste (Rio de Janeiro) e Sul do Brasil (Paraná, Santa Catarina e Rio Grande do Sul). No Rio Grande do Sul ocorre no Bioma Mata Atlântica, restrita à região dos Campos de Cima da Serra, coletada até o momento somente no município de Cambará do Sul, no Parque Nacional de Aparados da Serra. Ocorre em elevações entre 800 e 1800 m de altitude, em ambientes com solo úmido no interior de matas com araucária e matas nebulares das bordas do Planalto. No estado, C. cordifolia pode ser considerada, conforme IUCN (2001), como criticamente em perigo (CR B2b(ii); D).

Floresce durante o ano todo, com predominância nos meses de dezembro, janeiro e fevereiro. A espécie apresenta folhas cordadas, com nervuras secundárias impressas na face abaxial e longo pecíolo, característica exclusiva dentre as espécies estudadas. Além disso, os capítulos apresentam brácteas involucrais com indumento lanoso na face adaxial. $O$ epíteto faz referência às lâminas cordadas das folhas. Popularmente é conhecida como língua-de-vaca (Cabrera \& Klein 1973).

3. Chaptalia exscapa (Pers.) Baker, Fl. bras. 6: 379. 1884. Tussilago exscapa Pers., Syn. Pl. 2: 456. 1807. Leria exscapa (Pers.) DC., Anal. Mus. Paris 19: 68. 1812. Thyrsanthema exscapa (Pers.) Kuntze Revis. Gen. Pl. 1: 369. 1891. Tipo: URUGUAI. MONTEVIDÉU: Montevidéu, s.d., s.c. (Tipo: não localizado).

Fig. 2g-1

Plantas $1-6,5 \mathrm{~cm}$ alt. Raízes marrons. Folhas sésseis, lâminas coriáceas, elíptico-espatuladas, oblongas a oblanceoladas, 2,5-9 × 0,7-3,3 cm, base atenuada, margem crenado-denteada, ápice obtuso a agudo, face adaxial glabra, pilosa ou serícea, face abaxial tomentosa a lanosa. Escapo ausente na floração, na frutificação 1-7 cm compr., tomentoso a lanoso, ebracteado. Capítulo ereto; invólucro 1,3-2,7 × 1-3,5 cm, campanulado; brácteas involucrais $4-5$ seriadas, deltadas, obovadas a lanceoladas de ápice obtuso a agudo na floração e lanceoladas de ápice agudo na frutificação, glabras em ambas as faces, ou levemente pubescentes, ápice e nervura central de coloração verde. Flores do raio brancas, tubo 2,5-6; mm compr., lábio abaxial 2-9,3 mm compr., lábio adaxial quando presente irregularmente bífido; estilete 7-9 mm compr., ramos do estilete $0,8-2 \mathrm{~mm}$ compr. Flores intermediárias brancas, tubo 2,5-5,5 mm compr.; estilete 6-11 mm compr., ramos do estilete $0,5-2 \mathrm{~mm}$ compr. Flores do disco brancas, tubo 4,5-7 mm compr., lábio abaxial 0,5-2 mm compr., lábio adaxial 1-1,6 mm compr.; estilete 5-9 mm compr., ramos do estilete $0,7-1,8$ mm compr.; anteras 3-5 mm compr., apêndices apicais obtusos a agudos. Cipsela fusiforme 6-8 costada, 3-6 mm compr., levemente constrito no ápice, tricomas esparsos; pápus marrom a dourado, 13-18 mm compr.

Material selecionado: Barra do Quaraí, 30¹1'19"S, 57²9'97'W, 21.IV.2011, fr., E. Pasini \& A. Aita 863 (ICN). Bom Jesus, 17.VIII.2002, fr., R. Wasum 1529 (HUCS). Caxias do Sul, 18.XI.2010, fr., E. Pasini 562 (ICN). Encruzilhada do Sul, 1.X.1984, fl., M. Sobral \& Y. Folz 3042 (MBM). Esmeralda, 13.IX.1987, fl. e fr., $R$. Wasum et al. (HUCS 3220). Pelotas, 19.V.1959, fl., J.C. Sacco 1187 (HB, HBR, PEL). Porto Alegre, 5.X.1933, fl., B. Rambo (PACA 512). Santa Maria, 27.V.1994, fr., L.Z. Arthur (SMDB 5441). Taquara, 7.IV.1958, fr., $J$. Mattos 6018 (HAS).

Material adicional seleccionado: ARGENTINA. BUENOS AIRES: Part. General Pueyrredón, Sierra de los Padres, 18.II.1953, fl., Gautier 25 (LP). CÓRDOBA: Dep. Punilla. Sierra Grande, Copina, 29.XII.1935, fl., A. Burkart 7543 (SI). CORRIENTES: Dep. Monte Caseros, Monte Caseros, 20.VIII.1950, fr., E. Nicora 5379 (LP). ENTRE RÍOS: Dep.. Concordia, Pedernal, III.1934, fr., Friedman 364 (LP). SAN LUIS: Dep. Ayacucho, Sololosta, 24.I.1934, fr., Pastore 6652 (SI). BRASIL. PARANÁ: campo de Capinare, auf der Serra Geral, II.1891, fl., Ule 1820 (GH). SANTA CATARINA: Bom Retiro, 26.I.1957, fl., L. Smith \& R. Reitz 10483 (LP). URUGUAY. CANELONES: Canelones, V.1926, fr., Herter 195A (LP). FLORES: Río Yí y arroyo Marincho, 13.IV.1937, fr., B. Rosengurtt B1503 (LP). MALDONADO: Cerro Pan de Azúcar, 18.V.1937, B. Rosengurtt B1836 (LP). SORIANO: Juan Jackson, estancia "Monzón-Heber", IV.1943, fr., Gallinal et al. PE-4235 (LP).

Distribui-se pela Argentina, Região Sul do Brasil (Paraná, Santa Catarina e Rio Grande do Sul), Chile, Peru e Uruguai. No Rio Grande do Sul é encontrada em ambos os biomas presentes no estado, Pampa e Mata Atlântica, nas regiões fisiográficas da Campanha, Campos de Cima da Serra, Depressão Central, Encosta do Sudeste, Encosta Inferior do Nordeste, Encosta Superior do Nordeste e Serra do Sudeste. A espécie habita formações campestres em solos arenosos ou rochosos, secos, úmidos ou em afloramentos rochosos, onde as populações formam extensos aglomerados. Conforme IUCN (2001) a espécie enquadra-se como fora de perigo (LC) por ser amplamente distribuída no estado e apresentar extensas populações ocorrendo em diversas fisionomias vegetacionais campestres. 
Chaptalia exscapa floresce e frutifica durante todo o ano. A espécie pode ser facilmente reconhecida por não apresentar escapo floral, característica exclusiva dentre as espécies do gênero. Entretanto, na frutificação o escapo desenvolve-se, permitindo que as cipselas sejam dispersadas por anemocoria. Burkart (1944) reconhece as variedades $C$. exscapa var. exscapa (como var. typica), C. exscapa var. chilensis (DC.) Burkart e C. exscapa var. microcephala Domke. No Rio Grande do Sul somente Chaptalia exscapa var. exscapa é encontrada. $\mathrm{O}$ epíteto refere-se à ausência de escapo floral. A espécie é popularmente conhecida como língua-de-vaca (Cabrera \& Klein 1973).

4. Chaptalia graminifolia (Malme) Cabrera, Fl. Ilustr. Catarin. 1: 60. 1973. Chaptalia piloselloides (Vahl) Baker var. graminifolia Malme, Kongl. Svenska Vetensk. Acad. Handl. 12: 115. 1933. Tipo: BRASIL. PARANÁ: Inter Capão Grande et Villa Velha, 12.III.1904, P. Dusén 4062 (Lectótipo (aqui designado): GH (00061276!), B (provavelmente destruído), Foto F (16003!),

Fig. 3a-f

Plantas 14-35 cm alt. Raízes enegrecidas. Folhas sésseis, lâminas coriáceas, lineares ou linearoblanceoladas, 6-40 × 0,3-1,6 cm, base atenuada, margem revoluta, inteira ou raramente denteada, ápice agudo, face adaxial glabra ou pubescente na nervura central, face abaxial tomentosa a lanosa. Escapo 7-56 × 0,07-0,2 cm, piloso a tomentoso, eventualmente lanoso no ápice, brácteas 7-16, subuladas, roxas ou esverdeadas, alargadas na base. Capítulo ereto; invólucro 1-1,5 × 1,5-2 cm, turbinado ou cilíndrico; brácteas involucrais 4-5 seriadas, linear-lanceoladas a lanceoladas, glabras em ambas as faces, esverdeadas ou roxas no ápice. Flores do raio brancas, tubo 1-4 mm compr., lábio abaxial 5,6-9,5 mm compr., lábio adaxial ausente; estilete 4,3-6 mm compr., ramos do estilete $0,2-1$ $\mathrm{mm}$ compr. Flores intermediárias brancas ou lilases, 1,3-4,5 mm compr.; estilete 4,7-7 mm compr., ramos do estilete $0,2-1 \mathrm{~mm}$ compr. Flores do disco brancas, tubo 3,3-5,6 mm compr., lábio abaxial 1-1,6 mm compr., lábio adaxial 1-1,8 mm compr.; estilete 4-7 $\mathrm{mm}$ compr., ramos do estilete $0,3-0,7 \mathrm{~mm}$ compr.; anteras 2,7-3,7 mm compr., apêndices apicais agudos, obtusos ou truncados. Cipsela fusiforme, 4-5 costada, 6-9 mm compr., rostrada, rostro $0,5-3 \mathrm{~mm}$ compr., glabra; pápus branco, 5-9 mm compr.

Material selecionado: Cambará do Sul, 10.XII.2010, fr., E. Pasini et al. 550 (ICN). São Francisco de Paula, $29^{\circ} 19^{\prime} 21^{\prime \prime}$ S, 5007'83”W, 15.III.2011, fr., E. Pasini \&
A. Aita 750 (ICN). São José dos Ausentes, 20.XI.2004, fl., G. Hatschbach et al. 78271 (MBM).

Material adicional selecionado: BRASIL. SANTA CATARINA: Campo Alegre, 29.IX.2001, fl., O.S. Ribas et al. 3701 (MBM, PACA). Garuva, 20.XII.2006, fl., J.M. Silva \& C.A. Andrade 5466 (MBM). Palhoça, 6.IV.1956, fl., R. Reitz \& R.M. Klein 2983 (HBR). Quatro Barras, 11.X.1964, fl., G. Hatschbach 11716 (MBM). Rancho Queimado, 24.X.1957, fl., R. Reitz \& R.M. Klein 5412 (HBR). São Bonifácio, 31.V.1968, fl., R. Reitz \& R.M. Klein 18132 (HBR). São Francisco do Sul, 3.IX.1960, fl., R. Reitz \& R.M. Klein 9760

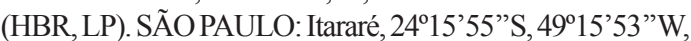
10.IX.1993, fl., V.C. Souza et al. 4071 (ESA, MBM).

Distribui-se pelas Regiões Sudeste (Minas Gerais e São Paulo) e Sul (Paraná, Santa Catarina e Rio Grande do Sul) do Brasil. No Rio Grande do Sul ocorre no Bioma Mata Atlântica, na região fisiográfica dos Campos de Cima da Serra, em elevações entre 800 a $1400 \mathrm{~m}$ de altitude. As populações vegetam em campos limpos e secos, porém, é frequentemente encontrada em ambientes de elevada umidade como banhados ou turfeiras de Sphagnum spp. Os indivíduos encontram-se distribuídos de maneira esparsa, geralmente junto a aglomerados de espécies da família Poaceae. As folhas são semelhantes às folhas de Poaceae, o que pode dificultar na identificação quando em estado vegetativo. No estado do Rio Grande do Sul, Chaptalia graminifolia pode ser considerada de acordo com IUCN (2001) como criticamente ameaçada (CR A3a(ii)), pois encontra-se restrita a apenas uma região e suas populações são esparsas e pequenas, ocorrendo somente em áreas campestres ecologicamente frágeis como banhados e turfeiras. Além disso, nos Campos de Cima da Serra, plantações de silviculturas como de Pinus spp. aumentam o risco de diminuição das populações.

Floresce durante todos os meses do ano. A espécie é morfologicamente semelhante a Chaptalia runcinata e C. piloselloides, entretanto, difere por possuir cipselas glabras, folhas com margem inteira e revoluta e com dimensões maiores (até $56 \mathrm{~cm}$ de comprimento). Popularmente é conhecida como língua-de-vaca-folha-de-grama (Cabrera \& Klein 1973). O epíteto é devido à semelhança de suas folhas com as de Poaceae.

5. Chaptalia ignota Burkart, Physis (Buenos Aires) 11: 102. 1932. Tipo: ARGENTINA. BUENOS AIRES: Dep. Buenos Aires, s.d., A. Burkart 2153 (Holótipo: SI!; Isótipos: LP!, GH!, SI!). $\quad$ Fig. 3g-1 Plantas $13-50 \mathrm{~cm}$ alt. Raízes enegrecidas. Folhas sésseis, lâminas papiráceas, elípticas a 


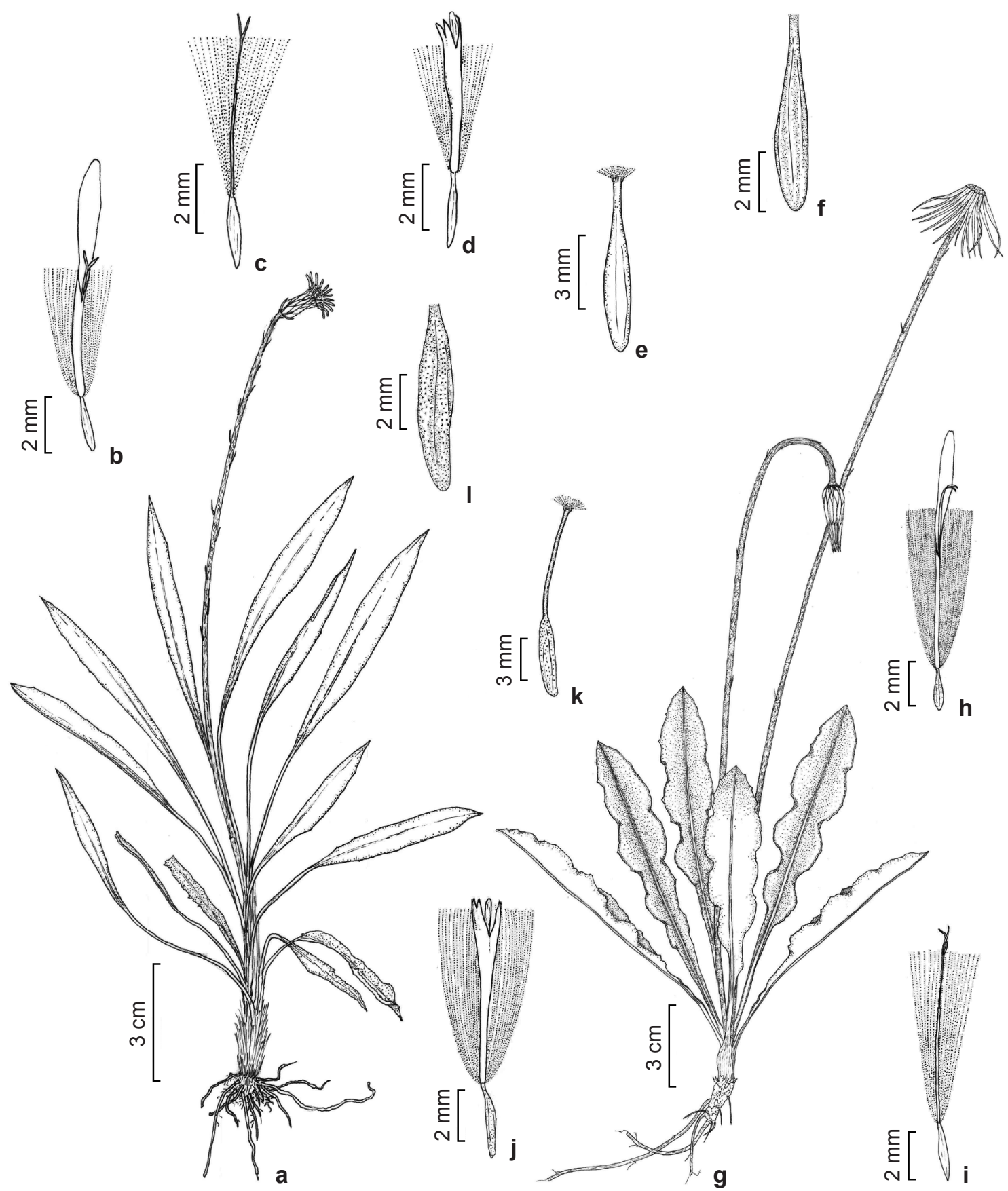

Figura 3 - a-f. Chaptalia graminifolia (Dusén) Cabrera - a. hábito (Pasini \& Aita 750); b. flor do raio; c. flor intermediária; d. flor do disco; e. cipsela; f. detalhe da cipsela (Pasini et al. 550). g-1. Chaptalia ignota Burkart - g. hábito (Pasini 469); h. flor do raio; i. flor intermediária; j. flor do disco; k. cipsela; 1. detalhe da cipsela (Burkart et al. 23847). Adaptado de Pasini \& Ritter (2012).

Figure 3 - a-f. Chaptalia graminifolia (Dusén) Cabrera - a. habit (Pasini \& Aita 750); b. ray floret; c. intermediate floret; d. disc floret; e. cypsela; f. detail of the cypsela (Pasini et al. 550). g-1. Chaptalia ignota Burkart - g. habit (Pasini 469); h. ray floret; i. intermediate floret; j. disc floret; k. cypsela; 1. detail of the cypsela (Burkart et al. 23847). Adapted from Pasini \& Ritter (2012). 
oblanceoladas, 7-22 ×0,6-3,5 cm, base atenuada, margem crenado-denteada, ápice agudo, face adaxial glabra, face abaxial tomentosa. Escapo 11$46 \mathrm{~cm}$ compr., tomentoso, brácteas 5-13, subuladas, marrom-escuras. Capítulo nutante; invólucro 1-3 $\times 1,7-6 \mathrm{~cm}$, cilíndrico a campanulado; brácteas involucrais 4-5 seriadas, subuladas, tomentosas, ápice e margens castanho-avermelhadas. Flores do raio brancas a rosadas, tubo 3-8,3 mm compr., lábio abaxial 4-14 mm compr., lábio adaxial quando presente irregularmente bífido; estilete 8,4-12 mm compr., ramos do estilete 0,9-3 mm compr. Flores intermediárias brancas a rosadas, tubo 3-7,5 mm compr.; estilete 7,5-13 mm compr., ramos do estilete 1,3-3 mm compr. Flores do disco brancas, tubo 8,2-9,2 mm compr., lábio abaxial 1,5-5 mm compr., 3 denteado, lábio adaxial bífido, 1,8-2,3 mm compr.; estilete 8,7-12 mm compr., ramos do estilete 0,7-1,5 mm compr.; anteras 3,6-4,8 mm compr., apêndices apicais obtusos. Cipsela fusiforme, 5-8 costada, 5-8,5 mm compr., rostrada, rostro 5-16 mm compr., tricomas esparsos; pápus branco ou amarelo-roxo, 13-20 mm compr.

Material selecionado: Aceguá, $31^{\circ} 34^{\prime} 97^{\prime}$ 'S, 5408'39'W, 7.XI.2010, fr., E. Pasini 469 (ICN).

Material adicional selecionado: ARGENTINA. BUENOS AIRES: Part. San Isidro, III.1932, fl. e fr., A. Burkart 4395 (SI). CORRIENTES: 14.XI.1934, fl., A. Burkart 6878 (SI). ENTRE RIOS: Dep. Colón, fr., A. Pozzi (SI 115700); Dep. Paraná, 31.X.1962, fl e fr., A. Burkart et al. 23847 (SI). URUGUAI. CERRO LARGO: I.1941, fl. e fr., G. Aragone \& B. Rosengurtt 4598 (LP). PAYSANDU: I.1942, fl.e fr., J. Chebataroff 7204 (LP). RIO NEGRO: San Javier, I.1940, fl., J. Chebataroff 10271 (LP).San Antonio, X.1931, fl., Rosengurtt B-2681 (LP).

Distribui-se pela Argentina, Região Sul do Brasil (Rio Grande do Sul) e Uruguai. No Rio Grande do Sul, possui apenas uma coleta (E. Pasini 469 ICN) na região fisiográfica da Campanha, Bioma Pampa. Chaptalia ignota vegeta em formações campestres limpas, em solos úmidos, podendo ser encontrada também em áreas com influência antrópica, como beiras de rodovias. No Rio Grande do Sul a espécie pode ser considerada, segundo IUCN (2001), como criticamente em perigo (CR B2b(ii); D), por suas populações estarem restritas a apenas uma localidade e a espécie ter sido coletada apenas uma vez.

Floresce durante o ano inteiro. Chaptalia ignota é morfologicamente próxima de C. nutans, entretanto apresenta folhas lanceoladas, crenadodenteadas, nunca liradas e habita somente formações campestres, não sendo encontrada em interior ou bordas de mata. $\mathrm{O}$ epíteto da espécie deriva da palavra de origem latina ignotus que significa desconhecido. Não foram encontrados na literatura ou no material examinado nomes populares atribuídos à espécie.

6. Chaptalia integerrima (Vell.) Burkart, Darwiniana 6: 576. 1944. Tussilago integerrima Vell., F1. Flumin. Icon. 8: t. 140. 1831. Tipo: (Lectótipo: designado por Burkart (1944), ilustração em Fl. Flumin. Icon. 8: t. 140. 1831!). Leria nutans (L.) DC. var sinuata Less., Linnaea 5: 354. 1830. Leria sinuata (Less.) DC., Prodr. 7 (1): 42.1838. Chaptalia sinuata (Less.) Baker, Fl. bras. 6 (3): 378. 1884, sin. nov.

Fig. $4 \mathrm{a}-\mathrm{f}$

Plantas 16-50 cm alt. Raízes cinzaamareladas a vermelho-alaranjadas. Folhas sésseis, lâminas papiráceas a coriáceas, elípticas, oblongas, oblongo-lanceoladas, lanceoladas oblanceoladas ou linear-oblanceoladas, 3-40 × 1-4,5 cm, base atenuada, margem inteira, denticulada, denteada, crenado-denteada ou serreada, ápice agudo, eventualmente apiculado, face adaxial glabra, pilosa ou tomentosa, face abaxial tomentosa a lanosa. Escapo 14-67 × 0,1-0,2 cm, tomentoso a lanoso, ebracteado. Capítulo recurvado a nutante; invólucro 1,5-2,5 × 1,8-2,5 cm, cilíndrico; brácteas involucrais 5-8 seriadas, subuladas, tomentosas na face adaxial, glabras na face abaxial, eventualmente ápice lilás. Flores do raio brancas, rosadas ou begeclaras, tubo 3,5-7 mm compr., lábio abaxial 5-10,5 mm compr., lábio adaxial irregularmente bífido ou ausente; estilete 7,5-14 mm compr., ramos do estilete 1,3-3,2 mm compr. Flores intermediárias lilases ou bege-claras, 1,3-8,5 mm compr.; estilete 7-13,5 mm compr., ramos do estilete 1,3-2,7 mm compr. Flores do disco brancas ou lilases, tubo 6,8$11 \mathrm{~mm}$ compr., lábio abaxial 0,7-2,8 mm compr., lábio adaxial, 1,3-3,3 mm compr.; estilete 7,5-15 mm compr., ramos do estilete $0,5-1,3 \mathrm{~mm}$ compr.; anteras 3,8-9 mm compr., apêndices apicais obtusos, agudos ou truncados. Cipsela fusiforme, 4-6 costada, 10-25,7 mm compr., rostrada, rostro 4-20 mm compr., tricomas esparsos; pápus branco, brancoamarelado ou amarelo-roxo, 8-20 mm compr.

Material selecionado: Alegrete, 27.IX.2008, fl., $W$. Heberle (ICN 157298). Bom Jesus, 21.X.2004, fl., G. Hatschbach et al. 78318 (MBM). Caçapava do Sul, 12.X.2000, fl., A. Knob \& S. Bordingnon 6497 (SALLE). Cachoeira do Sul, VIII.1985, fr., O. Bueno et al. 4360 (HAS). Caxias do Sul, 18.XI.2010, fr., E. Pasini 568 (ICN). Esmeralda, 7.XI.1981, fl., S. Miotto \& E. Franco (ICN). Nonoai, III.1945, fl., B. Rambo 

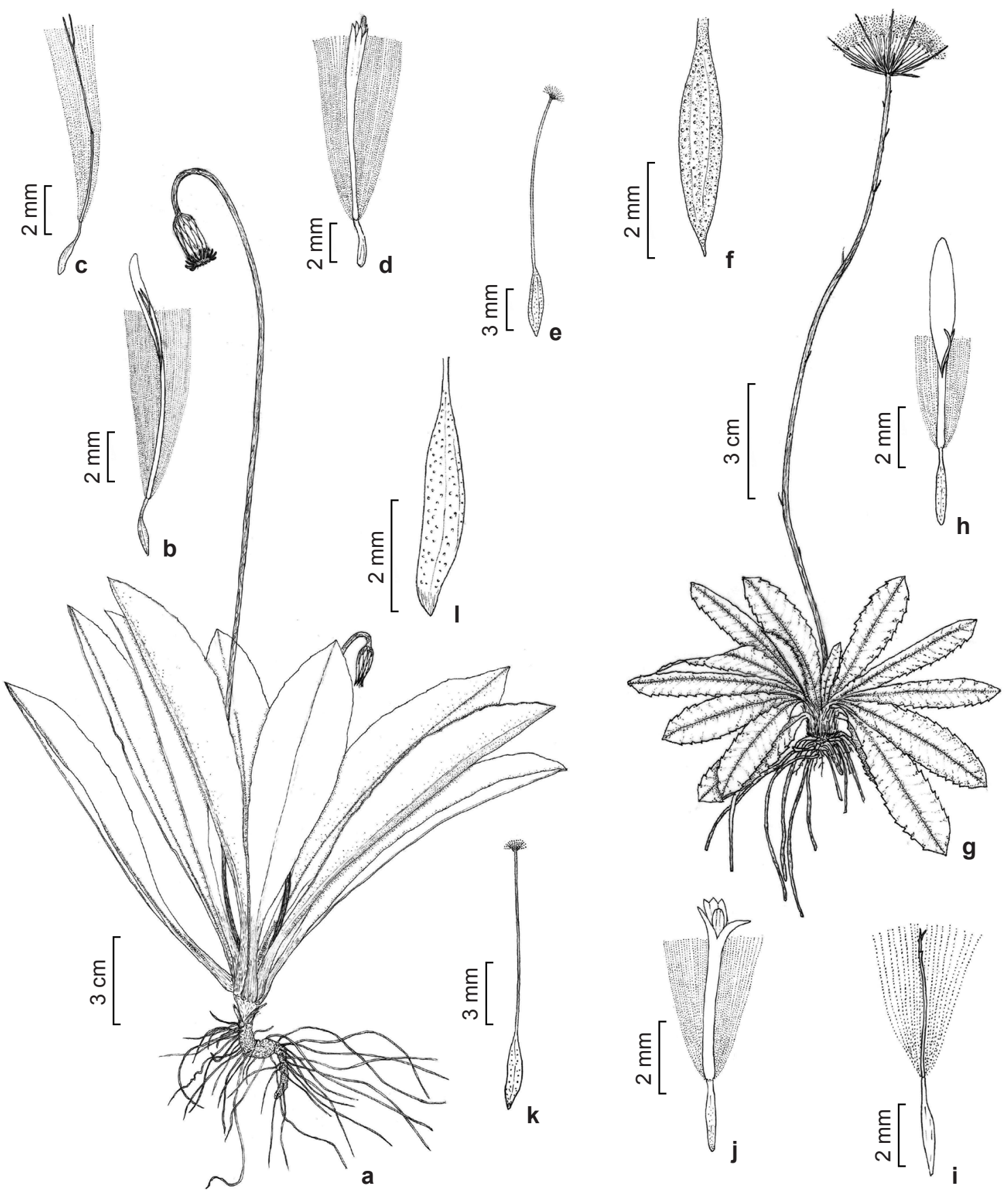

Figura 4 - a-f. Chaptalia integerrima (Vell.) Burkart - a. hábito (Pasini 568); b. flor do raio; c. flor intermediária; d. flor do disco; e. cipsela; f. detalhe da cipsela (Pasini s.n. ICN 166198). g-1. Chaptalia mandonii (Sch.Bip.) Burkart - g. hábito (Pasini 565); h. flor do raio; i. flor intermediária; j. flor do disco; k. cipsela; 1. detalhe da cipsela (Barbosa et al. 693).

Figure 4 - a-f. Chaptalia integerrima (Vell.) Burkart - a. habit (Pasini 568); b. ray floret; c. intermediate floret; d. disc floret; e. cypsela; f. detail of the cypsela (Pasini s.n. ICN 166198). g-1. Chaptalia mandonii (Sch.Bip.) Burkart - g. habit (Pasini 565); h. ray floret; i. intermediate floret; j. disc floret; k. cypsela; 1. detail of the cypsela (Barbosa et al. 693). 
SJ (PACA 28584). Morrinhos do Sul, 16.XII.1995, fl., J.A. Jarenkow \& M. Sobral 2891 (PEL). Pelotas, 12.III.1956, fl., Schlichting (PACA 63104). Passo Fundo, 28.X.1987, fl. e fr., N. Silveira 6724 (HAS). Porto Alegre, 3.VI.1980, fl., O. Bueno 2556 (HAS). Rosário do Sul, 3.V.1986, fr., R. Wasum 1525 (US). São Borja, 12.XII.1955, fr., A. Corrêa (PEL 399). São Leopoldo, 24.X.1936, fl., J. Dutra 1394 (ICN). São Sepé, 2.X.1988, fl., R. Wasum et al. 4553 (US). Santa Maria, 26.X.1994, fl. e fr., L.Z. Ethur (SMDB 5435). Santa Maria, 10.VI.1937, fr., Rau 83 (LP). Taquara, 2944'14'S, 50³9'39'W, 3.IX.2003, fl., A. Knob \& S. Bordignon 7473 (SALLE).Torres, 27.IX.1985, fl. e fr., R. Frosi et al. 408 (HAS).Tupanciretã, XII.1986, fl., M. Sobral et al. 5321 (ICN).Viamão, 2.X.2010, fr., E. Pasini (ICN 166198).

Material adicional selecionado: BRASIL. BAHIA: Feira de Santana, $12^{\circ} 15^{\prime}$ S, 38 $38^{\circ}$ 'W, 20.IX.1980, fl. e fr., L.R. Noblick (HUEFS 2032, MBM 152720). DISTRITO FEDERAL: Brasília, 28.XI.1975, fr., Oldengurger \& Mecenas 1959 (US). GOIÁS: Mineiros, 16.XI.1973, fr., G. Hatschbach \& C. Koczicki 33328 (MBM). MATO GROSSO: Parecis, 31.X.1943, fl. e fr., J.T. Baldwin Jr. 3133 (LP). MATO GROSSO DO SUL: Bonito, 11.X.2003, fl., G. Hatschbach et al. 76136 (MBM). MINAS GERAIS: São Roque de Minas, 14.X.1994, fl., R. Romero et al. 4579 (HUFU, MBM). PARANÁ: Balsa Nova, 1.XI.2005, fl. e fr., C. Kozera \& A. Sanches 2495 (MBM). RIO DE JANEIRO: Rio de Janeiro, XI.1879,fl., Glaziou 11060 (SI). SANTA CATARINA: Florianópolis, 1.VII.1991, fl., M.H. de Queiroz (FLOR 492). SÃO PAULO: Santa Cruz, 26.X.1992, fl., R. Wasum (HUCS 8696).

Distribui-se pela Argentina, Bolívia, Paraguai, Peru (Burkart 1944) e Regiões CentroOeste (Goiás, Mato Grosso e Mato Grosso do Sul), Nordeste (Bahia), Sudeste (Minas Gerais, Rio de Janeiro e São Paulo) e Sul (Paraná, Santa Catarina e Rio Grande do Sul) do Brasil e Uruguai. No Rio Grande do Sul é amplamente distribuída em ambos os Biomas (Mata Atlântica e Pampa), ocorrendo em formações campestres ou áreas com influência antrópica. Ocorre em solos secos ou úmidos onde os indivíduos distribuem-se de forma esparsa, ocorrendo também em bordas de mata. A espécie enquadra-se de acordo com IUCN (2001) como fora de perigo (LC) por ser amplamente distribuída no Estado e estar presente em uma gama diversa de fisionomias vegetacionais campestres, até mesmo em áreas altamente antropizadas.

Floresce durante todo o ano. Constatou-se, através dos materiais de herbários revisados e coletas no campo, que a espécie é morfologicamente semelhante a Chaptalia sinuata, também observado por Burkart (1944), Cabrera \& Klein (1973) e
Mondin (1996). As características morfológicas utilizadas para diferenciar os dois táxons podem ser observadas conjuntamente em uma mesma população, tornando-se difícil o reconhecimento dos mesmos. Chaptalia sinuata foi distinta de C. integerrima por caracteres vegetativos e reprodutivos, como folhas com margens retrorsadenteadas, crenadas ou sinuadas; escapos curtos e espessos e raízes avermelhadas. Flores do raio com lábio adaxial reduzido e lábio abaxial 3-dentado. Flores do disco com longas corolas; ramos do estilete 1,5-2 $\mathrm{mm}$ compr. e cipselas com rostro espesso (Burkart 1944). Todos estes caracteres, entretanto, apresentam variações nos espécimes analisados, e.g., folhas com margens inteiras e retrorso-denteadas no mesmo espécime (Cabrera 8037, Schultz 3511, Klein 4505). Além disso, observou-se espécimes de $C$. sinuata que apresentam os caracteres acima mencionados e outros considerados típicos de $C$. integerrima, i.e, raízes cinza-amareladas (e.g., Cabrera 6910), flores do raio sem lábio adaxial (e.g., Montes 3718) e cipselas com rostro filiforme (e.g., Wasum et al. 4553). Não obstante, os caracteres flores do raio e intermediárias de coloração bege-clara em $C$. integerrima e flores do raio rosadas e flores intermediárias lilases em $C$. sinuata, também mostrou sobreposição (e.g., Knob 7473, Rambo 53026, 38211 , Sobral 3047). Devido a isso, C. sinuata é considerada aqui como sinônimo de $C$. integerrima.

$\mathrm{O}$ epíteto refere-se às folhas com margem inteira ou denticulada. Chaptalia integerrima é conhecida popularmente como língua-de-vaca (Cabrera \& Klein 1973).

7. Chaptalia mandonii Sch.Bip. ex Burkart, Darwiniana 6: 551. 1944. Tipo: BOLÍVIA. LA PAZ: Larecaja, X.1858, Mandon 11 (Holótipo: B 16005! (destruído); Lectótipo (aqui designado): GOET, Imagem digitalizada!

Fig. 4g-1

Plantas 6-30 cm alt. Raízes marrons. Folhas sésseis, lâminas coriáceas, oblanceoladas, lanceoladas ou lineares, 1,8-13,5 × 0,4-2 cm, base atenuada, margem inteira, denteada ou serreada a pinnatisecta, eventualmente revoluta, ápice agudo ou acuminado, face adaxial glabra ou levemente pubescente, nervuras secundárias impressas, face abaxial tomentosa a lanosa. Escapo 2,8-33 × 0,06-0,2 cm, piloso a lanoso, brácteas 5-15, subuladas, alargadas na base, de coloração esverdeada na base e lilás no ápice. Capítulo ereto ou nutante; invólucro $1-1,8 \times 1,2-2 \mathrm{~cm}$, turbinado 
a campanulado; brácteas involucrais 4-5 seriadas, lanceoladas a subuladas, glabras em ambas as faces ou levemente pubescentes, esverdeadas na floração, na frutificação com ápice lilás. Flores do raio brancas ou verde-claras, tubo 1-2,8 mm compr., lábio abaxial 5,6-8 mm compr., lábio adaxial ausente ou 0,2 mm compr.; estilete 4-5,7 mm compr., ramos do estilete 0,5-1 mm compr. Flores intermediárias brancas ou lilases, 1,7-4,5 mm compr.; estilete 3,8-6 mm compr., ramos do estilete $0,7-1 \mathrm{~mm}$ compr. Flores do disco brancas, tubo 4-5,5 mm compr., lábio abaxial 0,6-1 mm compr., lábio adaxial 1,4-1,8 mm compr.; estilete 5-6 mm compr., ramos do estilete 0,4-1,2 mm compr.; anteras 2,2-3,5 mm compr., apêndices apicais obtusos ou agudos. Cipsela fusiforme, 4-5 costada, 8-16 mm compr., rostrada, rostro 3,5-12 mm compr., tricomas em toda a superfície; pápus branco, 5-10 mm compr.

Material selecionado: Bom Jesus, 28 34'50' S, 50²7'71"W, 17.III.2011, fl. e fr., E. Pasini \& A. Aita 802 (ICN). Cambará do Sul, 10.XII.2010, fr., E. Pasini et al. 820 (ICN). Caxias do Sul, 18.XI.2010, fr., E. Pasini 565 (ICN). Esmeralda, 29.III.1982, fl. e fr., L.A. Cestaro (HAS 28495). Passo Fundo, IV.2009, fr., M. Savaris 103 (ICN). Porto Alegre, 3003'19'S, 51'07'47'W, 9.V.2007, fr., A.C. Fernandes \& M.R. Ritter (ICN 158287). Soledade, 7.XI.1983, fr., J. Mattos 25102 (HAS).

Material adicional selecionado: BRASIL. DISTRITO FEDERAL: Chapada da Contagem, 26.X.1965, fr., Irwin et al. 9547 (US). PARANÁ: Almirante Tamandaré, 23.IX.1957, fl. e fr., G. Hatschbach 4100 (MBM). Campina Grande do Sul, 23.X.2001, fr., E. Barbosa et al. 693 (MBM). SANTA CATARINA: Bom Jardim da Serra, 29.III.1996, fr., D.B. Falkenberg 7856 (FLOR). Irienópolis, 26.X.1971, fl. e fr., Reitz \& Klein 13574 (HBR, MBM, PACA). SÃO PAULO: São Paulo, XII.1833, est., Riedel 1792 (SI).

Distribui-se pela Argentina, Bolivia, Uruguai e Regiões Sul (Paraná, Santa Catarina e Rio Grande do Sul), Centro-Oeste (Distrito Federal) e Sudeste (São Paulo) do Brasil. No Rio Grande do Sul ocorre no Bioma Mata Atlântica, nas regiões fisiográficas dos Campos de Cima da Serra, Depressão Central e Planalto Médio, embora seja comumente encontrada nos Campos de Cima da Serra em elevações entre 800 e $1400 \mathrm{~m}$ de altitude. A espécie ocorre em formações campestres, distribuídas em solos secos ou úmidos. Conforme IUCN (2001), a espécie pode ser considerada como fora de perigo (LC) por ser encontrada em diversas fisionomias vegetacionais campestres e estar amplamente distribuída na parte nordeste do estado.

Floresce durante todo o ano, predominantemente nos meses de dezembro a maio. Chaptalia mandonii assemelha-se morfologicamente a $C$. runcinata e $C$. piloselloides. Durante a revisão de herbários constatou-se que a semelhança entre os táxons citados fez com que muitos exemplares fossem identificados erroneamente. Chaptalia mandonii diferencia-se das outras duas espécies por apresentar folhas de consistência coriácea, fortemente denteadas com dentes retrorsos e nervuras secundárias impressas e marcadas na face adaxial. Entretanto, a principal característica que a distingue é a presença de papilas fusiformes em toda a superfície da cipsela e a presença de rostro com dimensões maiores (7-12 $\mathrm{mm}$ de comprimento). Na literatura não foram encontrados nomes populares.

8. Chaptalia nutans (L.) Pol., Linnaea 41: 582. 1877. Tussilago nutans L., Syst. Nat. ed. 10. 2: 1214. 1759. Leria nutans (L.) DC., Ann. Mus. Natl. Hist. Nat. 19: 68. 1812. Gerbera nutans (L.) Sch. Bip., Bot. Voy. Herald: 313. 1856. Thyrsanthema nutans (L.) Kuntze, Revis. Gen. Pl. 1: 369. 1891. Tipo: AMÉRICA, s.l., s.d., s.c. (Lectótipo: designado por Simpson (1975); LINN (995.5), Imagem digitalizada!).

Fig. 5a-f

Plantas 6-82 cm alt. Raízes enegrecidas. Folhas sésseis, lâminas papiráceas, liradas, 4,5-38 $\times 1,7-10 \mathrm{~cm}$, base atenuada, margem crenadodenteada, ápice agudo, face adaxial glabra ou levemente pubescente, face abaxial tomentosa a lanosa. Escapo $2-79 \times 0,1-0,4 \mathrm{~cm}$, piloso a tomentoso, ebracteado. Capítulo nutante; invólucro 1,2-2,4 × 0,8-3 cm, cilíndrico ou campanulado; brácteas involucrais 5-6 seriadas, lanceoladas a subuladas, glabras em ambas as faces ou pubescente na face abaxial, ápice e nervura central lilases. Flores do raio brancas ou lilases, tubo 3-8 mm compr., lábio abaxial 5-9 mm compr., lábio adaxial pouco desenvolvido ou ausente; estilete 6,5-10 mm compr., ramos do estilete $1-1,8 \mathrm{~mm}$ compr. Flores intermediárias brancas, 2-6 mm compr.; estilete 7,8-10 $\mathrm{mm}$ compr., ramos do estilete $0,5-2 \mathrm{~mm}$ compr. Flores do disco brancas, tubo 5-9,5 mm compr., lábio abaxial 1-1,7 mm compr., lábio adaxial 1-1,5 mm compr.; estilete 7-10,2 mm compr., ramos do estilete 0,5-1,2 mm compr.; anteras 2,6-3,8 mm compr., apêndices apicais obtusos. Cipsela fusiforme, 5-6 costada, 7-15 mm compr., rostrada, rostro 4-12 mm compr., tricomas esparsos; pápus branco, 8-13 mm compr. Material selecionado: Bom Jesus, 15.I.1942, fl., $B$. Rambo (PACA 8818). Caçapava do Sul, 20.IX.1986, fl. 


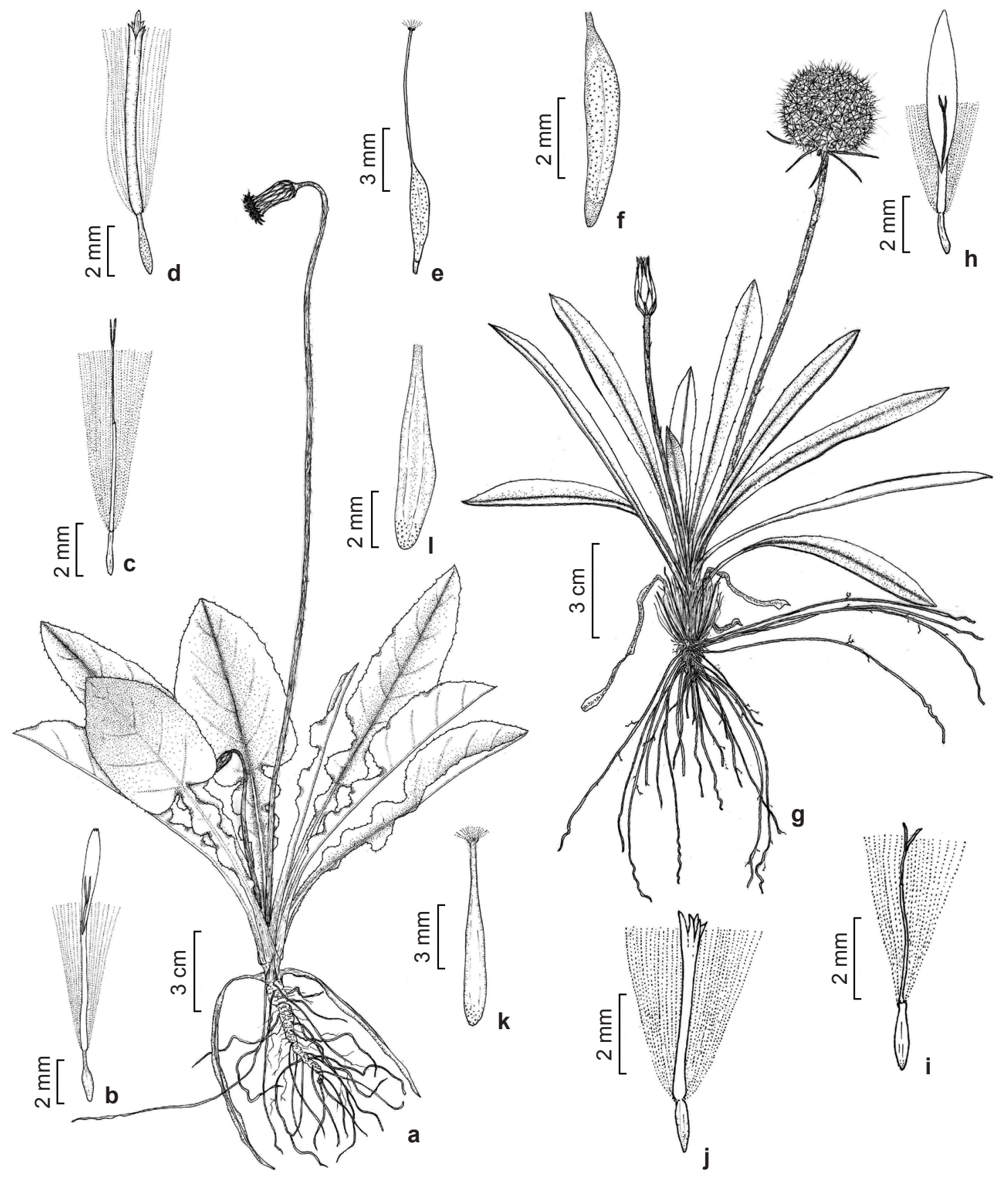

Figura 5 - a-f. Chaptalia nutans (L.) Pol. - a. hábito; b. flor do raio; c. flor intermediária; d. flor do disco; e. cipsela; f. detalhe da cipsela (Pasini 430). g-1. Chaptalia piloselloides (Vahl) Baker - g. hábito; h. flor do raio; i. flor intermediária; j. flor do disco; k. cipsela; 1. detalhe da cipsela (Pasini \& Aita 866).

Figure 5 - a-f. Chaptalia nutans (L.) Pol. - a. habit; b. ray floret; c. intermediate floret; d. disc floret; e. cypsela; f. detail of the cypsela (Pasini 430). g-1. Chaptalia piloselloides (Vahl) Baker - g. habit; h. ray floret; i. intermediate floret; j. disc floret; k. cypsela; 1. detail of the cypsela (Pasini \& Aita 866). 
e fr., R. Wasum et al. (HUCS 1955). Cambará do Sul, 21.IV.2004, f1., A.S. Klein et al. (CRI 8603). Caxias do Sul, 22.X.1988, fl., R. Wasum et al. 4729 (MO). 30.X.1988, fl., R. Wasum et al. 4800 (MO). 3.XI.2005, fl., E. Pasini 35 (HUCS). Canoas, XI.1938, fl., Luis c66 (LP). Erechim, 20.X.1984, fl., S.A. Martins 550 (HAS). Farroupilha, 5.IX.1978, fl., Bueno 1011 (SI). Ijuí, XI.1981, fr., J. Mattos \& N. Mattos 22233 (HAS). Montenegro, 28.IX.1949, fl., Sehnem 3898 (SI). Flores da Cunha, 5.X.1986, fl., R. Wasum 2072 (WIS). Porto Alegre, X.1944, fl., B. Rambo 27156 (LP). Rio Grande, 15.XII.1986, fl. e fr., M. Ritter 86 (ICN). Santa Cruz do Sul, X.1986, fr., M. Sobral 5156 (ICN). Santa Maria, 13.XI.2004, fl., J.F. Gonçalves (SMDB 9801). São Francisco de Paula, 18.IX.2010, fl., E. Pasini 430 (ICN). Torres, 24.IX.1987, fl., N. Silveira 9362 (HAS). São Leopoldo, IX.1942, fl., R. Reitz 426 (M).

Material adicional selecionado: BRASIL. ACRE: Seringal Monte Alegre, 6.I.1944, fl., B. Baldwin 4734 (LP). BAHIA: Conde, 30.V.1996, fr., M.C. Ferreira \& T. Jost 1006 (MBM). DISTRITO FEDERAL: Brasília, 24.XI.1980, fl., Heringer et al. 5783 (MO). GOIÁS: $17^{\circ} 12^{\prime}$ S, 51 $47^{\prime}$ W, 22.X.1964, fl., H.S. Irwin \& T.R. Soderstrom (MBM 60397, NY 7175). MATO GROSSO DO SUL: Bonito, 9.X.2003, fl., G. Hatschbach et al. 76070 (MBM). MINAS GERAIS: 7.I.1989, fl. e fr., $A$. Krapovickas \& C.L. Cristóbal 42829 (CTES). PARANÁ: Curitiba, 6.X.1975, fl., L.T.H. Dombrowski 6011 (CTES, MBM). RIO DE JANEIRO: Rio de Janeiro, Glaziou 15026 (LP). SANTA CATARINA: Bom Retiro, Campo dos Padres, 17.XII.1948, fl., R. Reitz 3647 (PACA, SI). SÃO PAULO: São Paulo, 10.X.1939, fl. e fr., W. Hoehne (MBM 215089, SPF 14093).

Distribui-se amplamente em toda a América tropical, desde o sul dos Estados Unidos até a região do Rio de La Plata na Argentina e Uruguai, não ocorrendo no Chile (Burkart 1944; Cabrera \& Klein 1973; Nesom 1995). No Brasil ocorre em todas as Regiões. No Rio Grande do Sul a espécie distribui-se amplamente em todas as regiões fisiográficas, onde pode ser encontrada em vegetação campestre de solos secos ou rochosos, bordas e interior de matas em solos úmidos e áreas com intensa influência antrópica. Apesar disso, é frequentemente encontrada em locais úmidos e sombreados. Trata-se da espécie mais conhecida e coletada do gênero, apresentando ampla gama de registros nos herbários visitados. Conforme os critérios estipulados pelo IUCN (2001) a espécie enquadra-se como fora de perigo (LC) por ser amplamente distribuída no estado e estar presente até mesmo em áreas altamente antropizadas.

Floresce nos meses de julho a março. A espécie é facilmente distinguida por possuir folhas liradas e longos escapos florais de até $79 \mathrm{~cm}$ de comprimento. Na medicina popular, Chaptalia nutans é utilizada para diversos fins. Cabrera \&
Klein (1973) e Empinotti \& Duarte (2006) citam o uso das folhas aquecidas sobre contusões, traumatismos, ferimentos, hemorragias ou sobre as têmporas a fim de aliviar dores de cabeça. As folhas e raízes são utilizadas internamente para febres, problemas pulmonares, doenças de pele e sífilis (Cabrera \& Klein 1973), como béquico e laxante (Empinotti \& Duarte 2006). O epíteto refere-se à posição nutante dos capítulos quando em floração. Popularmente é conhecida como língua-de-vaca ou arnica-do-campo por apresentar as mesmas utilidades etnobotânicas que a arnicaverdadeira Arnica montana L. (Cabrera \& Klein 1973; Empinotti \& Duarte 2006).

9. Chaptalia piloselloides (Vahl) Baker, Fl. Bras. 6 (3): 378. 1884. Perdicium piloselloides Vahl, Skr. Naturhist.-Selsk. 2: 38. 1791. Tussilago sinuata (Vahl) Pers., Syn. Pl. 2: 456. 1807. Tipo: URUGUAI. MONTEVIDÉU: Montevidéu, s.d., Commerson s.n. (Tipo: não localizado).

Fig. 5g-1

Plantas 3-20 cm alt. Raízes marrons. Folhas sésseis, lâminas papiráceas, elípticas, oblanceoladas, lanceoladas ou lineares, 3-21 $\times$ 0,4-1,2 cm, base atenuada, margem irregularmente denteada ou serreada, ápice agudo ou acuminado, face adaxial glabra, face abaxial tomentosa. Escapo 1-32 × 0,2-0,3 cm, piloso a lanoso, brácteas 4-12, subuladas, alargadas na base, de coloração esverdeada. Capítulo ereto; invólucro 1-1,7 × 1,2-2 $\mathrm{cm}$, turbinado a campanulado; brácteas involucrais 4-5 seriadas, lanceoladas, glabras em ambas as faces ou levemente pubescentes, verde-claras. Flores do raio brancas, tubo 1,8-3,2 mm compr., lábio abaxial 2-7,5 mm compr., lábio adaxial ausente; estilete 3,8-7 mm compr., ramos do estilete $0,8-1,2 \mathrm{~mm}$ compr. Flores intermediárias brancas, 0,6-4,2 mm compr.; estilete 3,7-7 mm compr., ramos do estilete 0,7-1,2 mm compr. Flores do disco brancas, tubo 3,5-7 mm compr., lábio abaxial 0,5-2,4 mm compr., lábio adaxial 1,3-2,7 mm compr.; estilete 3,7-7 mm compr., ramos do estilete $0,4-1 \mathrm{~mm}$ compr.; anteras 2,4-4,3 mm compr., apêndices apicais agudos. Cipsela fusiforme, 7-8 costada, 6-7,5 mm compr., rostrada, rostro de 1,5-5 $\mathrm{mm}$ compr., tricomas fusiformes restritos à base; pápus branco, alaranjado ou marrom 8,5-12 mm compr.

Material selecionado: Barra do Quaraí, 21.IV.2011, fl. e fr., E. Pasini \& A. Aita 866 (ICN). Bom Jesus, 15.I.1942, est., B. Rambo (PACA 8915). Pelotas, 19.V.1959, fr., J.C. Sacco 1186 (HB, HBR, MBM, PEL). Porto Alegre, 5.XI.1933, fl., B. Rambo 511 (LP). 24.VIII.2010, N.I. Matzenbacher (ICN 166206). Rio Grande, 15.VII.1986, 
fl., J.A. Jarenkow 394 (PEL). São Leopoldo, 17.V.1946, fl., E. Henz (PACA 33426). Sapucaia do Sul, 5.IX.1945, fl., B. Rambo (PACA 29545). Uruguaiana, 28.IV.1988, fl. e fr., N. Silveira 7578 (HAS).

Material adicional selecionado: ARGENTINA. BUENOS AIRES: Part. Avellaneda, 16.VI.1928, fl., A. Burkart 2208 (SI). CORRIENTES: 3.VI.1945, fr., A. Soriano 1688 (LP). ENTRE RIOS: Dep. Chajarí, 25.IV.1952, fl. e fr., E.G. Nicora 6188 (SI). MISIONES: Dep. Candelaria, 26.VII.1974, fl. e fr. Ahumada \& Eskuche 3194 (SI). URUGUAY. CANELONES: Arroyo Canelón Grande, J. Chebataroff 3904 (LP). FLORES: Río Jí y Arroyo Marincho, 13.IV.1937, fl. e fr., B. Rosengurtt B1504 (LP). FLORIDA: FCCE Timote, Arroyo Timote, 20.IV.1937, fl. e fr., B. Rosengurtt B1650 (LP). MALDONADO: Cerro de las Animas, fl. e fr., J. Chebataroff 3752 (LP). MONTEVIDEO: Cerrito, V.1926, fr., Herter $196 b$ (LP). SORIANO: Juan Jackson, estancia "Monzón-Heber", 22.IX.1940, fl., Gallinal et al. PE-4414 (LP).

Distribui-se pela Argentina, Paraguay, Uruguai e Região Sul do Brasil (Rio Grande do Sul). No Rio Grande do Sul ocorre no Bioma Pampa, nas regiões fisiográficas da Campanha, Depressão Central e Encosta Inferior do Nordeste, habitando formações campestres úmidas, campos rupestres ou bordas de matas. Durante o estudo encontrou-se extensas populações vegetando no Parque Estadual do Espinilho, Unidade de Conservação no extremo oeste do estado, onde a vegetação é classificada como Estepe Gramíneo-Lenhosa ou Estepe Parque. As populações foram encontradas em solo arenoso, juntamente com espécies de inhanduvás características do parque: Prosopis affinis Spreng. e Prosopis nigra Hieron. (Fabaceae). Chaptalia piloselloides encontra-se, segundo o IUCN (2001), como fora de perigo (LC) no Rio Grande do Sul.

Floresce de janeiro a outubro. No presente trabalho observou-se que a espécie é frequentemente identificada em materiais de herbário como Chaptalia runcinata. Isto se deve aos táxons serem morfologicamente muito próximos, sendo que a identificação de ambos depende de caracteres florais como a morfologia da cipsela e do escapo floral. Chaptalia piloselloides apresenta cipselas 7-8 costadas com rostros de menores dimensões (1,5-3 de comprimento), escapos florais mais espessos $(0,2-0,3$ $\mathrm{cm})$ e folhas com margens irregularmente denteadas, crenado-denteadas ou inteiras. Por outro lado, $C$. runcinata possui cipselas 4-6 costadas com rostros de maiores dimensões (5-4 $\mathrm{mm}$ de comprimento), escapos florais mais delgados $(0,09-0,2 \mathrm{~cm}$ de diâmetro) e folhas notavelmente denteadas. Apesar da diferença, Burkart (1994) ressalta que na zona de transição entre as duas espécies, isto é, no centro do estado, ocorrem indivíduos intermediários que podem ser interpretados como híbridos. Não foram encontrados na literatura nomes populares atribuídos à C. piloselloides.

10. Chaptalia runcinata Kunth, Nov. Gen. Sp. P1. 4 (ed. folio): 5. 1818. Thyrsanthema runcinata (Kunth) Kuntze, Revis. Gen. P1. 1: 369. 1891. Tipo: COLÔMBIA. In Andibus NovoGranatensis, s.d., F. Humboldt \& A. Bonpland 2031 (Lectótipo: designado por Nesom (1995), P; Imagem digitalizada: F!). Fig. 6a-f

Plantas 5-40 cm alt. Raízes marrons. Folhas sésseis, lâminas papiráceas, elípticas, oblongas, oblanceoladas ou lanceoladas, 3-17 × 0,3-1,5 $\mathrm{cm}$, base atenuada, margem retrorso-denteada ou serreada, ápice obtuso, agudo ou acuminado, face adaxial glabra ou levemente pubescente, face abaxial tomentosa. Escapo 2,5-38 × 0,09-0,2 cm, piloso a lanoso, brácteas 5-15, subuladas, alargadas na base, de coloração esverdeada na base e lilás no ápice. Capítulo ereto; invólucro $1-1,5 \times 0,8-2$ $\mathrm{cm}$, turbinado a campanulado; brácteas involucrais 4-5 seriadas, linear-lanceoladas, lanceoladas, levemente pubescentes ou glabras em ambas as faces, esverdeadas ou lilases. Flores do raio brancas, tubo 1,2-4 mm compr., lábio abaxial 4-8 mm compr., lábio adaxial ausente; estilete 3,4-6 mm compr., ramos do estilete 0,5-1 $\mathrm{mm}$ compr. Flores intermediárias brancas ou lilases, 0,9-5 mm compr.; estilete 3,6-7 mm compr., ramos do estilete $0,6-1 \mathrm{~mm}$ compr. Flores do disco brancas, tubo 3-6 mm compr., lábio abaxial 0,8-1,5 mm compr., lábio adaxial 1-1,8 mm compr.; estilete 3-7,2 mm compr., ramos do estilete 0,4-1 $\mathrm{mm}$ compr.; anteras 2,6-3,5 mm compr., apêndices apicais agudos. Cipsela fusiforme, 4-6 costada, 8-9 mm compr., rostrada, rostro 4-6 mm compr., tricomas fusiformes restritos a base da cipsela; pápus branco ou amarelo-roxo, 4-8,6 mm compr. Material selecionado: Aceguá, 29.VII.1998, fl., J.A. Jarenkow 3846 (FLOR, PEL, MBM). Bom Jesus, 17.VIII.2002, fl., J. Bordin 1 (HUCS, MBM). Cachoeira do Sul, 8.VII.1974, est., N.I. Matzenbacher 89 (ICN).Caxias do Sul, 17.IX.1988, fr., R. Wasum et al. 4473 (US). Canela, 2.VIII.1975, fl., M.C. Sidia \& M.L. Porto 49 (HAS). Capão do Leão, 29.VII.1988, fl., J.A. Jarenkow 885 (FLOR, ICN, PACA, PEL). Manuel Viana, 2939'71'S, 55²3'68'W, 23.IV.2011, fr., E. Pasini \& A. Aita 883 (ICN). Porto Alegre, 5.VII.1948, fl., B. Rambo 37426 (SI). Santa Maria, 14.VI.1994, fl., L.Z. Ethur (SMDB 5047). São Francisco de Paula, 30.IV.2010, fl., E. Pasini et al. 387 (ICN). São José dos Ausentes, 18.III.2011, fr., E. Pasini \& A. Aita 801 (ICN). Torres, 10.VIII.1994, fl., C. Mondin 957 

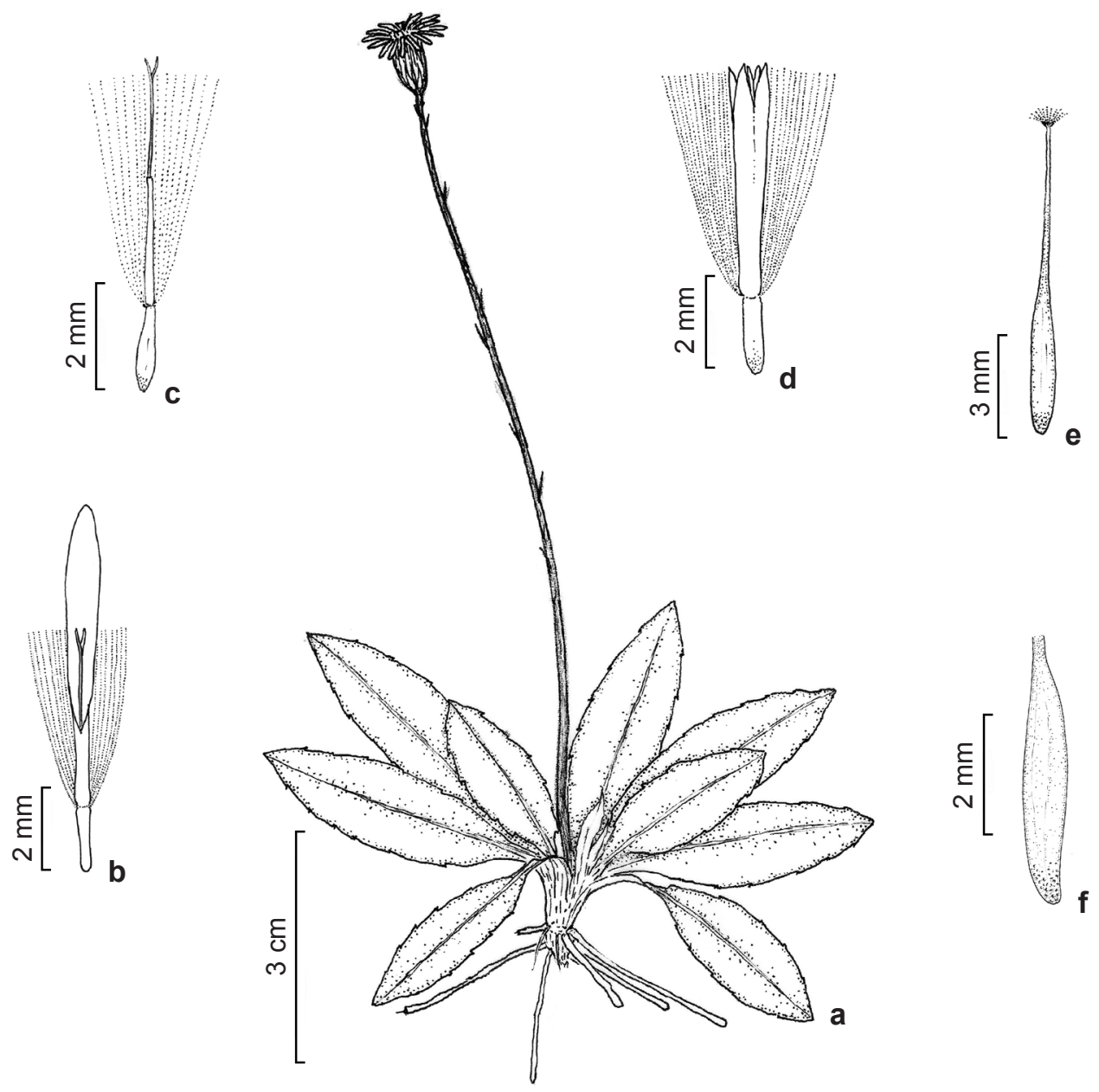

Figura 6 - a-f. Chaptalia runcinata Kunth - a. hábito (Pasini et al. 387); b. flor do raio; c. flor intermediária; d. flor do disco; e. cipsela; f. detalhe da cipsela (Pasini \& Aita 801).

Figure 6 - a-f. Chaptalia runcinata Kunth - a. habit (Pasini et al. 387); b. ray floret; c. intermediate floret; d. disc floret; e. cypsela; f. detail of the cypsela (Pasini \& Aita 801).

(ICN). Triunfo, 6.IX.1977, fr., I. Ungartetti 593 (HAS). Uruguaiana, 3.XI.1995, fr., S.M. Marodin (ICN 110394). Vacaria, 26.XII.1951, fl., B. Rambo SJ (PACA 51487). Veranópolis, 21.X.1983, fl., J. Mattos 25187 (HAS). Viamão, 26.XI.1979, fl., G.C. Hiltl 1004 (MPUC).

Material adicional selecionado: BRASIL. GOIÁS: Chapada dos Veadeiros, 13.XI.1996, fl., da Silva \& dos Santos 3236 (US). MINAS GERAIS: Gouveia, 13.XI.1971, fl., G. Hatschbach 27861 (MBM). PARANÁ: Quatro Barras, 11.X.1964, fl., G. Hatschbach 11716 (LP). RIO DE JANEIRO: Itatiaia, Estação Biológica, 2225'S, 4441'W, 7.I.1929, Smith 1723 (GH). SANTA CATARINA: Bom Jardim da Serra, 17.VIII.1996, fl., D.B. Falkenberg 8114 (FLOR). SÃO PAULO: São Paulo, 25.VI.1917, fl., F.C. Hoehne (LP 67459).

Distribui-se do México a Argentina, Regiões Centro-Oeste (Goiás), Sudeste (Minas Gerais, São
Paulo, Rio de Janeiro) e Sul (Paraná, Santa Catarina, Rio Grande do Sul) do Brasil. No Rio Grande do Sul a espécie ocorre em ambos os Biomas Mata Atlântica e Pampa, nas regiões fisiográficas da Campanha, Campos de Cima da Serra, Depressão Central, Encosta do Sudeste, Encosta Inferior do Nordeste, Encosta Superior do Nordeste, Litoral, Missões e Serra do Sudeste. Entretanto, é frequentemente encontrada na região dos Campos de Cima da Serra e Encosta Superior do Nordeste. A espécie vegeta em formações campestres abertas ou em bordas de matas, em solo seco ou úmido, onde pode ser observada em campos com afloramentos rochosos, assim como em banhados e turfeiras. Conforme IUCN (2001), Chaptalia runcinata encontra-se fora de perigo (LC) por ser amplamente 
distribuída em todas as regiões fisiográficas do estado, exceto no Alto-Uruguai.

Floresce durante todo o ano com predominância nos meses de julho a outubro. Além de ser confundida com Chaptalia piloselloides, a espécie é frequentemente identificada como C. mandonii nos materiais depositados em herbários. Entretanto, se diferencia por possuir cipselas com papilas restritas à base (vs. papilas distribuídas por toda a extensão da cipsela) e folhas com consistência papirácea ( $v s$. consistência coriácea), sem as nervuras secundárias impressas na face adaxial ( $v s$. nervuras impressas na face adaxial). $\mathrm{O}$ epíteto se refere às margens com dentes retrorsos, interpretado por Kunth como margens runcinadas. Popularmente é conhecida como língua-de-vaca (Cabrera \& Klein 1973).

\section{Agradecimentos}

$\mathrm{O}$ primeiro autor agradece a João Ricardo Vieira Iganci, Priscila Porto Alegre Ferreira, Jaqueline Durigon, Adriana Aita e Leandro Dal Ri as valiosas discussões e sugestões ao artigo. Agradecimentos também a Edson Luís de Carvalho Soares pelas ilustrações e montagem das figuras. O primeiro autor agradece à Coordenação de Aperfeiçoamento Profissional do Ensino Superior (CAPES) a bolsa concedida e à Universidade Federal do Rio Grande do Sul o auxílio financeiro nas saídas a campo.

\section{Referências}

Barroso, G.M. 1991. Sistemática de angiospermas do Brasil. Vol. 3. UFV, Viçosa. 326p.

Beentje, H. 2010. The Kew plant glossary: an illustrated dictionary of plant terms. Royal Botanic Gardens, Kew. 160p.

Boldrini, I.I.; Eggers, L.; Mentz, L.A.; Miotto, S.T.S.; Matzenbacher, N.I.; Longhi-Wagner, H.M.; Trevisan, R.; Schneider, A.A. \& Setubal, R.B. 2009. Flora. In: Boldrini, I.I. (coord.). Biodiversidade dos campos do planalto das araucárias. Ministério do Meio Ambiente, Brasília. Pp. 39-84.

Burkart, A. 1944. Estudio del género de Compuestas Chaptalia con especial referencia a las especies argentinas. Darwiniana 6: 505-594 \& pl. i-x.

Cabrera, A.L. \& Klein, R.M. 1973. Compostas. Tribo: Mutisieae. Flora Ilustrada Catarinense. Herbário Barbosa Rodrigues, Itajaí. 124p.
Empinotti, C.B. \& Duarte, M.R. 2006. Caracteres Anatômicos de arnica-do-campo: Chaptalia nutans. Acta Farmacéutica Bonaerense 25: 333-338.

Font Quer, P. 1953. Diccionario de botánica. Editorial Labor, Barcelona. 1244p.

Fortes, A.B. 1959. Geografia física do Rio Grande do Sul. Globo, Porto Alegre. 393p.

Funk, V.A.; Susana, A.; Stuessy, T.F. \& Bayer, R.J. (eds.). 2009. Systematics, evolution and biogeography of the Compositae. IAPT, Vienna. 1000p.

Gonçalves, E.G. \& Lorenzi, H. 2007. Morfologia vegetal: organografia e dicionário ilustrado de morfologia das plantas vasculares. Instituto Plantarum, Nova Odessa. 448p.

IBGE. 2004. Mapa de biomas do Brasil. Escala 1:5.000.000. Rio de Janeiro. Disponível em $<\mathrm{http}: / /$ mapas.ibge.gov.br/biomas2/viewer.htm.> Acesso em 18 Nov 2012.

IUCN. 2001. IUCN Red List Categories and Criteria: Version 3.1. IUCN Species Survival Commission. IUCN, Gland, Cambridge. ii +30 p.

Katinas, L.; Pruski, J.F.; Sancho, G. \& Telleria, M.C. 2008. The subfamily Mutisioideae (Asteraceae). Botanical Review 74: 469-716.

Mondin, C.A. 1996. A tribo Mutisieae Cass. (Asteraceae), sensu Cabrera, no Rio Grande do Sul e suas relações biogeográficas. Dissertação de Mestrado. Universidade Federal do Rio Grande do Sul, Porto Alegre. $161 \mathrm{p}$.

Monge, M. \& Roque, N. 2012. Chaptalia. In: Lista de espécies da flora do Brasil. Jardim Botânico do Rio de Janeiro. Disponível em <http://floradobrasil. jbrj.gov.br/2012/FB005269>. Acesso em $12 \mathrm{Fev}$ 2012.

Nesom, G.L. 1995. Revision of Chaptalia (Asteraceae: Mutisieae) from North America and continental Central America. Phytologia 78: 153-188.

Pasini, E. \& Ritter, M.R. 2012. Trichocline cisplatina (Asteraceae, Mutisieae), a new species form Southern Brazil and Uruguay. Phytotaxa 42: 19-25.

Radford, A.E. et al. 1974. Vascular plants systematics. Harper \& How, New York. 891p.

Roque, N. \& Bautista, H. 2008. Asteraceae: caracterização e morfologia floral. Editora da Universidade Federal da Bahia, Salvador. 69p.

Thiers, B. 2010 [continuously updated]) Index Herbariorum: A global directory of public herbaria and associated staff. New York Botanical Garden's Virtual Herbarium. Disponível em $<\mathrm{http}: / /$ sweetgum.nybg.org/ih/>. Acesso em 16 Out 2011. 